\title{
Investigation of Asphaltene Adsorption onto Zeolite Beta Nanoparticles to Reduce Asphaltene Deposition in a Silica Sand Pack
}

\author{
Sepideh Kashefi ${ }^{1}$, Mohammad Nader Lotfollahi ${ }^{1, *}$ and Abbas Shahrabadi ${ }^{2}$ \\ 1 Faculty of Chemical, Petroleum and Gas Engineering, Semnan University, Semnan - Iran \\ 2 Exploration and Production Division, Research Institute of Petroleum Industry (RIPI), Tehran - Iran \\ e-mail: mnlotfollahi@semnan.ac.ir \\ *Corresponding author
}

\begin{abstract}
Zeolite beta nanoparticles were used as a new asphaltene adsorbent for reducing asphaltene deposition during fluid injection into a silica sand pack. At first, the asphaltene adsorption efficiency and capacity of zeolite beta nanoparticles were determined by UV-Vis spectrophotometer. It was found that the proper concentration of nanoparticles for asphaltene adsorption was $10 \mathrm{~g} / \mathrm{L}$ and the maximum asphaltene adsorption onto zeolite beta was $1.98 \mathrm{mg} / \mathrm{m}^{2}$. Second, two dynamic experiments including co-injection of crude oil and n-heptane (as an asphaltene precipitant) with and without use of zeolite beta nanoparticles in the sand pack was carried out. The results showed that the use of zeolite beta nanoparticles increased the permeability ratio and outlet fluid's asphaltene content about $22 \%$ and $40 \%$ compared to without use of nanoparticles, respectively. Moreover, a model based on monolayer asphaltene adsorption onto nanoparticles and asphaltene deposition mechanisms including surface deposition, entrainment and pore throat plugging was developed to determine formation damage during co-injection of crude oil and n-heptane into the sand pack. The proposed model presented good prediction of permeability and porosity ratios with $A A D \%$ of 1.07 and 0.07 , respectively.
\end{abstract}

\section{INTRODUCTION}

Crude oil is composed of light to heavy hydrocarbons that based on the polarity and molecular structure is separated to four groups: Saturates, Aromatics, Resins, and Asphaltenes. The asphaltenes are the heaviest and polar cyclic components of crude oil that are insoluble in low molecular weight alkanes and soluble in light aromatics such as toluene [1]. One common problem during oil recovery is asphaltene instability due to changes of thermodynamic conditions. During oil production, the asphaltene flocs are formed slowly because of self-association and precipitated out of the oil phase. As a result, the asphaltene is deposited on the rock surfaces and effects on the rock properties such as permeability, porosity and wettability. It causes formation damage during oil production and transportation [2]. One of the effective methods for controlling asphaltene deposition is to use chemical additives such as surfactants [3,4], polymeric inhibitor [5] and adsorbents [6]. Up to now, several adsorbents were used for asphaltene adsorption from oil solution such as mineral surfaces (kaolin, calcite and dolomite) [6], clay and reservoir rocks [7, 8], metal surfaces (stainless steel and gold) $[9,10]$ and several kinds of metal and metal oxide nanoparticles $\left(\mathrm{MgO}, \mathrm{TiO}_{2}, \mathrm{NiO}, \mathrm{CaO}\right.$, $\mathrm{Fe}_{3} \mathrm{O}_{4}, \mathrm{Al}_{2} \mathrm{O}_{3}$, etc) [11-18]. The reasons of interest on using nanoparticles in recent years for asphaltene adsorption are the special properties of nanoparticles such as their high surface area to volume ratio, functionalizable surface and their smaller size that cause easier transportation in porous media and enhance the performance of fluid flow and oil 
recovery [14-16]. The amount of adsorbed asphaltene onto nanoparticles strongly depends on the type, surface chemistry of the nanoparticles and the kind of the interaction force between asphaltene and nanoparticles [11,12]. The asphaltene surface charge, Van der Waals force and acidbase interaction between surface of nanoparticles and polar asphaltene particles are different kinds of forces for asphaltene adsorption onto nanoparticles $[11,16,19]$.

Most of the previous studies showed that the nanoparticles are good choices for adsorption and catalytic oxidation of asphaltene in crude oil upgrading process $[11,13,19]$ while, limited researches have been carried out on using nanoparticles in porous media for asphaltene adsorption and consequently reduction of asphaltene deposition through oil flooding $[17,18,20]$.

The objective of this study was to investigate the potential application of zeolite beta nanoparticles as a new adsorbent for asphaltene adsorption from crude oil solution which reduces the asphaltene deposition during oil injection in a porous media. At first the capacity of zeolite beta nanoparticles for equilibrium adsorption of asphaltene was determined by UV-Vis spectrophotometer. Then two dynamic experiments including co-injection of n-heptane (as an asphaltene precipitant) and crude oil into a silica sand pack were conducted in the absence and presence of the zeolite beta nanoparticles. The changes of permeability and porosity ratios in a porous media were experimentally determined with the use of zeolite beta. The process was also mathematically modeled by a developed asphaltene deposition model. To our best knowledge, this is the first report on the use of zeolite beta nanoparticles in porous media for investigating of asphaltene deposition during oil injection.

\section{EXPERIMENTAL}

\subsection{Materials}

A crude oil from an Iranian reservoir on the south west of Iran $(A P I=33.74)$ was used in this study. Table 1 shows the specifications of the crude oil, which has about $1 \mathrm{wt} \%$ asphaltene content. The asphaltene particles were extracted from the crude oil according to IP-143 standard analysis [21]. The acid and base numbers of asphaltene were found to be 2.25 and 12.46 by potentiometric titration method, respectively [22]. These values confirmed the basic nature of asphaltene particles. The n-heptane (Merck, Germany, $>99 \%$ ) as asphaltene precipitant and toluene (Merck, Germany, $>99.8 \%$ ) as solvent were used.

The zeolite beta nanoparticles $(\mathrm{Si} / \mathrm{Al}=25)$ was supplied from Zeolyst International Company in USA. The properties of the zeolite beta are reported in Table 2. Moreover, the
TABLE 1

Specifications of the crude oil.

\begin{tabular}{l|l|l|l}
\hline Composition & mol.\% & Composition & mol.\% \\
\hline $\mathrm{C}_{1}$ & 0.00 & $\mathrm{C}_{6}$ & 13.81 \\
\hline $\mathrm{C}_{2}$ & 0.07 & $\mathrm{C}_{7}$ & 10.50 \\
\hline $\mathrm{C}_{3}$ & 0.45 & $\mathrm{C}_{8}$ & 8.06 \\
\hline $\mathrm{i}-\mathrm{C}_{4}$ & 0.95 & $\mathrm{C}_{9}$ & 11.76 \\
\hline $\mathrm{n}-\mathrm{C}_{4}$ & 4.63 & $\mathrm{C}_{10}$ & 7.81 \\
\hline $\mathrm{i}-\mathrm{C}_{5}$ & 2.89 & $\mathrm{C}_{11}$ & 7.86 \\
\hline $\mathrm{n}-\mathrm{C}_{5}$ & 3.39 & $\mathrm{C}_{12+}{ }^{\mathrm{b}}$ & 27.82 \\
\hline
\end{tabular}

$\rho_{\text {crude }}$ oil $=0.8519 \mathrm{~g} / \mathrm{cm}^{3}, \quad \mathrm{MW}_{\text {crude }}{ }_{\text {oil }}=216 \mathrm{~g} / \mathrm{g} \mathrm{mol}, \quad \mathrm{SG}_{\mathrm{C} 12+}=$ $0.8958, \mathrm{MW}_{\mathrm{C} 12+}=508 \mathrm{~g} / \mathrm{g} \mathrm{mol}$.

TABLE 2

Properties of the zeolite beta nanoparticles.

\begin{tabular}{l|l|l|l}
\hline $\begin{array}{l}\text { BET surface } \\
\text { area }\left(\mathrm{m}^{2} / \mathrm{g}\right)\end{array}$ & $\begin{array}{l}\text { External surface } \\
\text { area }\left(\mathrm{m}^{2} / \mathrm{g}\right)\end{array}$ & $\begin{array}{l}\text { Pore } \\
\text { size }(\mathrm{nm})\end{array}$ & $\begin{array}{l}\text { Surface } \\
\text { chemistry }^{\mathrm{a}}\end{array}$ \\
\hline 680 & 136 & $0.56-0.75$ & $\begin{array}{l}\text { Acidic } \\
(\text { acidity }=0.324 \\
\left.\mathrm{mmol} \mathrm{H}^{+} / \mathrm{g}\right)\end{array}$ \\
\hline
\end{tabular}

${ }^{a}$ Obtain by titration method [23].

liquid paraffin (by-product of refining crude oil of Iran, density $=0.88 \mathrm{~g} / \mathrm{cm}^{3}$ ) was applied as a base fluid for dispersing nanoparticles.

\subsection{Estimation of Proper Amount of Nanoparticles for Asphaltene Adsorption}

Several amounts of zeolite beta nanoparticles $(1,2.5,5,7.5$, 10,15 and $20 \mathrm{~g} / \mathrm{L}$ ) were added to the $1500 \mathrm{mg} / \mathrm{L}$ asphaltenetoluene solutions. The initial concentration of $1500 \mathrm{mg} / \mathrm{L}$ is the good choice for this experiment. Because it is lower than critical clustering concentration of asphaltene in toluene $(\approx 2000 \mathrm{mg} / \mathrm{L})$ [24]. Therefore, with selection of this concentration, the contribution of the asphaltene selfassociation to the adsorbed mass of the asphaltene was decreased [25]. Next, the prepared solutions were being shaken at $200 \mathrm{rpm}$ until the equilibrium was achieved. Based on the performed preliminary experiments, $4 \mathrm{~h}$ shaking time was found to be sufficient to reach equilibrium and the amount of adsorbed asphaltene onto zeolite beta nanoparticles did not change with increasing contact time. After that, the nanoparticles containing the adsorbed asphaltene were separated by centrifuging at $5000 \mathrm{rpm}$ for $30 \mathrm{~min}$ [14]. The light absorbance values of the residual solutions were measured by UV-Vis spectrophotometer (Perkin-Elmer Instruments Lambda 35) at the wavelength of $410 \mathrm{~nm}$. The standard solutions 
with the specified concentrations of asphaltenes were used to create a calibration curve of UV-Vis absorbance and pure toluene was used as a blank $[14,20]$.

To determine the proper amount of nanoparticles for asphaltene adsorption, the adsorption efficiency $(E)$ was calculated by following equation [26]:

$$
E=\frac{\left(C_{0}-C_{e}\right)}{C_{0}} \times 100
$$

where $C_{0}$ and $C_{e}$ are the initial and equilibrium concentrations of asphaltene in solutions $(\mathrm{mg} / \mathrm{L})$, respectively.

\subsection{Batch Adsorption Experiments}

The proper amount of zeolite beta nanoparticles was added to asphaltene-toluene solutions with concentration range between 100 and $3000 \mathrm{mg} / \mathrm{L}$. The solutions were shaken at $200 \mathrm{rpm}$ for $4 \mathrm{~h}$. Then the nanoparticles containing adsorbed asphaltene were separated by centrifuging at $5000 \mathrm{rpm}$ for $30 \mathrm{~min}$. The amount of asphaltene in residual solutions was measured by UV-Vis spectrophotometer at the wavelength of $410 \mathrm{~nm}$ [14]. The adsorption of asphaltene onto nanoparticles was measured from the change in the concentration of asphaltene in toluene before and after adding the nanoparticles. The adsorbed amount of asphaltene onto the nanoparticles was calculated by [20]:

$$
q_{e}=\frac{C_{0}-C_{e}}{m}\left(\frac{V}{A_{n}}\right)
$$

where $q_{e}$ is the equilibrium adsorbed amount of asphaltene $\left(\mathrm{mg} / \mathrm{m}^{2}\right), V$ is the volume of solution (L), $m$ is the dry mass of nano-particles $(\mathrm{g}), C_{0}$ is the initial concentration of asphaltene in the solution $(\mathrm{mg} / \mathrm{L})$ and $C_{e}$ is the equilibrium concentration of asphaltene in the solution $(\mathrm{mg} / \mathrm{L}), A_{n}$ is the surface area of nanoparticles $\left(\mathrm{m}^{2} / \mathrm{g}\right)$.

The Langmuir isotherm model was used to correlate the experimental equilibrium data of asphaltene adsorption onto zeolite beta nanoparticles [11, 13, 14, 20, 25]. The Langmuir model is presented as follows [27]:

$$
q_{e}=\frac{q_{\max } k_{L} C_{e}}{1+k_{L} C_{e}}
$$

where $q_{e}$ is the equilibrium adsorbed amount of asphaltene $\left(\mathrm{mg} / \mathrm{m}^{2}\right), q_{\max }$ is the maximum amount of adsorbed asphaltene for the monolayer adsorption on adsorbent surfaces $\left(\mathrm{mg} / \mathrm{m}^{2}\right), C_{e}$ is the equilibrium concentration of asphaltene in the solution $(\mathrm{mg} / \mathrm{L})$, and $k_{L}$ is the Langmuir equilibrium adsorption constant $(\mathrm{L} / \mathrm{mg})$.

\subsection{Sand Pack Preparation}

In this research a silica sand pack was prepared and used as porous media for investigating the asphaltene deposition process with and without the use of nanoparticles. At first, the silica sands (Tavan Silice, Iran) were washed by deionized water to remove any impurities and placed in an oven at $333 \mathrm{~K}$ for $12 \mathrm{~h}$ to dry them. The silica sand particles had 297-595 micron diameter that were obtained by passing them through sieves with $30-50$ mesh sizes. A stainless steel cylinder with $21 \mathrm{~cm}$ length and $3.5 \mathrm{~cm}$ inside diameter was used and filled with approximately $500 \mathrm{~g}$ of prepared silica sands by simultaneously packing and shaking. Figure 1 shows a schematic view of the experimental setup used in this work.

The setup consists of several sections such as: The silica sand pack; cylinders for transferring samples (water, nheptane and crude oil with or without nanofluid); positive displacement pumps for allowing fluid displacement under constant flow rate; differential pressure transducer that measures the pressure differences between the inlet and outlet of the sand pack; sampling vial to collect produced fluids; check valves and data acquisition system.

\subsection{Nanofluid Preparation}

For nanofluid preparation, the proper amount of zeolite beta nanoparticles was dispersed in liquid paraffin as a base fluid. The base fluid should be a clear liquid for better observation of nanoparticle stability. Nanoparticles dispersion procedure was conducted using a probe ultrasonic $(400 \mathrm{~W}$ and $24 \mathrm{kHz})$ to break agglomerates of nanoparticles in the fluid and make stable suspension $[28,29]$. It was observed with naked eyes that the nanofluid was uniformly dispersed for $24 \mathrm{~h}$ and the complete sedimentation happened after three days. The size of zeolite beta nanoparticles in the liquid solution was about $50 \mathrm{~nm}$, as measured by dynamic light scattering analyzer (DLS, Malvern Instruments, Ltd., Worcestershire, UK).

\subsection{Dynamic Experiments}

To analyze asphaltene deposition process during fluid injection into the sand pack and to investigate the effect of zeolite beta nanoparticles in this process, two dynamic experiments, DE-1 and DE-2, were conducted. The first dynamic experiment (DE-1) was co-injection of crude oil and n-heptane as an asphaltene precipitant into the sand pack. The second dynamic experiment (DE-2) was coinjection of n-heptane and crude oil in the presence of zeolite beta nanoparticles. The DE-1 experiment involved the following steps:

- At first, the sand pack was vacuumed and saturated with water to determine the pore volume of porous media. How much water it has been adsorbed will be considered as pore volume (PV).

- The initial porosity of the sand pack was calculated by dividing the PV to the total volume $(\emptyset=38 \%)$. 


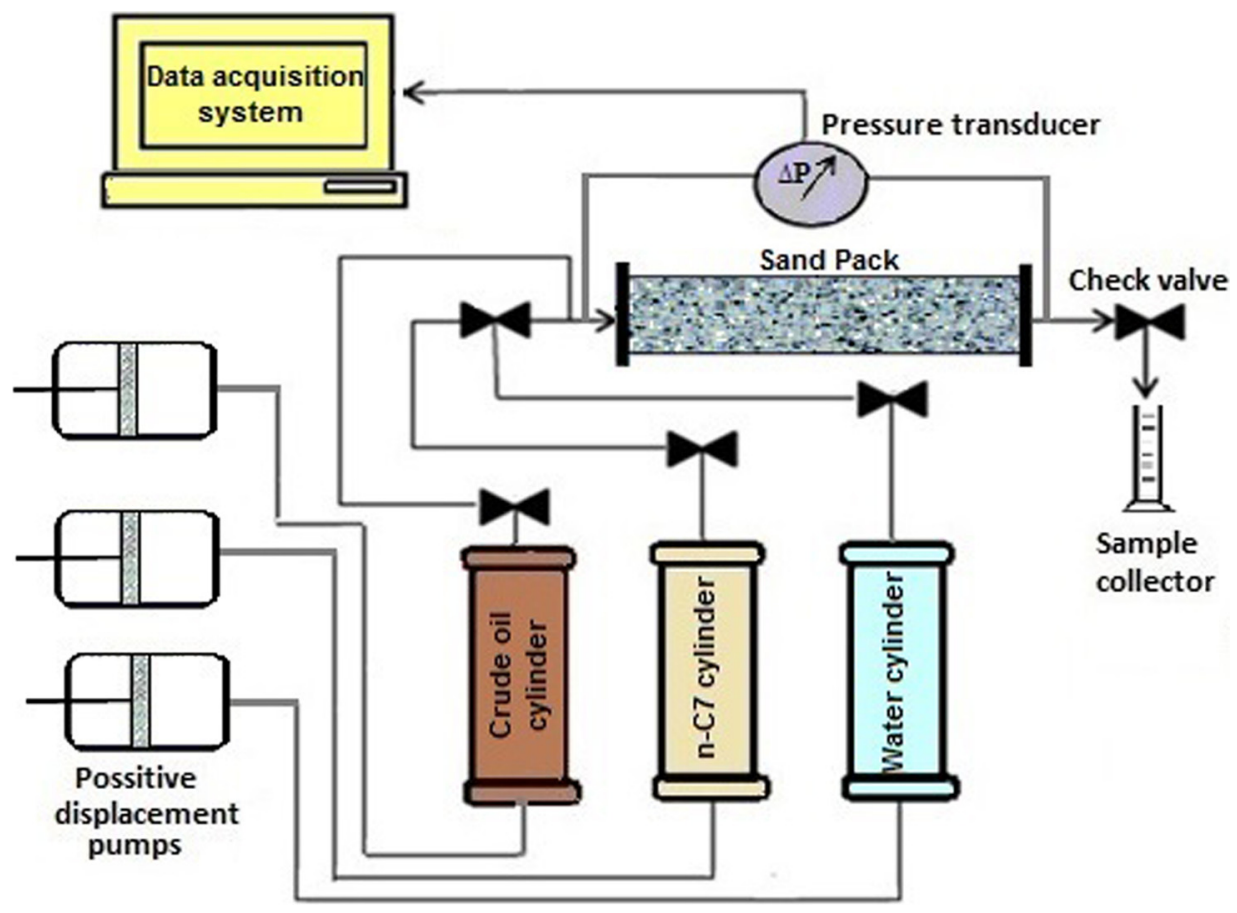

Figure 1

Schematic view of fluid injection setup.

- The absolute permeability was measured by water injection into the sand pack with constant flow rate. The pressure transducer was used to record the pressure differences $(\Delta \mathrm{P})$ between two ends of the sand pack. The absolute permeability was estimated by following Darcy's law [30] which was equal to $775 \mathrm{md}$.

$$
k=\left(\frac{Q}{\Delta P}\right)\left(\frac{L \mu}{A}\right)
$$

where $k$ is permeability (d), $Q$ is fluid flow rate $\left(\mathrm{cm}^{3} / \mathrm{s}\right)$, $\Delta P$ is pressure differences (bar), $\mu$ is fluid viscosity (cp), $L$ is length of the sand pack $(\mathrm{cm}), A$ is cross-sectional area of the sand pack $\left(\mathrm{cm}^{2}\right)$.

- The crude oil with $1 \mathrm{wt} \%$ initial asphaltene content was injected into the sand pack by positive displacement pump at a constant flow rate for displacing the water. The oil injection was continued until no more water produced in outlet and the irreducible water saturation was found by subtracting the outlet volume of water from initial volume of saturated water in the sand pack (swi $\approx 25 \%$ ).

- The crude oil was injected into the sand pack at a constant flow rate for measuring the initial oil permeability $\left(k_{0}=469 \mathrm{md}\right)$.

- The co-injection of crude oil and n-heptane was started inside the sand pack at same injection rates $\left(50 \mathrm{~cm}^{3} / \mathrm{h}\right)$. The $\Delta \mathrm{P}$ was measured by pressure transducer and shown by the data acquisition system at a specified time intervals. The fluid injection continued until the pressure difference was stabled.

- By using recorded $\Delta \mathrm{P}$ and measured mixture viscosity, the permeability ratios were continuously calculated by Darcy's law (Eq. 4).

- Produced fluids from outlet end of the sand pack during several PV of fluid injection were collected in samplers to measure asphaltene content.

- Finally, the toluene was being injected continuously to remove any precipitated asphaltene formed due to nheptane injection into the sand pack and to prepare the setup for second experiment.

The second dynamic experiment (DE-2) was carried out to study the effect of nanoparticles on the formation damage as following steps:

- The porosity and absolute permeability were calculated by water injection as above procedure $(\emptyset=38 \%, k=1194$ md).

- The crude oil/nanofluid solution was injected into the sand pack for finding the irreducible water saturation (swi= $32 \%$ ).

- The initial oil permeability was calculated by crude oil/ nanofluid solution injection at constant flow rate and using Darcy's law $\left(k_{0}=294 \mathrm{md}\right)$.

- At the end, co-injection of n-heptane and crude oil/ nanofluid solution into the sand pack was started at same injection rates $\left(50 \mathrm{~cm}^{3} / \mathrm{h}\right)$ to record pressure differences. 
TABLE 3

Measured viscosities of the fluids in DE-1 and DE-2 experiments.

\begin{tabular}{l|l}
\hline Fluid & Viscosity (cp) \\
\hline Crude oil & 8.28 \\
\hline Crude oil/nano fluid solution & 11.79 \\
\hline $\begin{array}{l}\text { Miscible fluid in DE-1 (50 vol\% crude oil and } \\
50 \text { vol\% n-heptane) }\end{array}$ & 5.12 \\
\hline $\begin{array}{c}\text { Miscible fluid in DE-2 (50 vol\% crude oil/nano } \\
\text { fluid and } 50 \text { vol\% n-heptane) }\end{array}$ & 5.81 \\
\hline
\end{tabular}

The permeability ratios after miscibility were continuously calculated with using recorded $\Delta P$, flow rate of miscible fluid $\left(100 \mathrm{~cm}^{3} / \mathrm{h}\right)$ and mixture viscosity by Darcy's law.

- It should be noted that before the miscibility condition in both dynamic experiments, the fluid composition was unknown and a reliable value for the fluid viscosity could not be estimated [31,32]. The viscosities of different solutions including crude oil solution in DE-1, crude oil/ nanofluid solution in DE-2 and mixture of n-heptane and oil solution after miscibility in both dynamic experiments were measured by Stabinger Anton paar SVM 3000 viscometer at ambient condition. The measured viscosities are reported in Table 3. It can be observed that the viscosity of crude oil/nanofluid solution in DE-2 experiment is higher than the viscosity of crude oil without nanoparticles in DE-1 experiment.

\section{MODELING OF ASPHALTENE DEPOSITION IN THE SAND PACK}

In this study, the Wang and Civan model [33] was modified with adding Langmuir adsorption term to model the asphaltene deposition in the case of using nanoparticles during miscible fluid injection into the sand pack. This new term represented the monolayer asphaltene adsorption onto nanoparticles. The proposed model included surface deposition, entrainment and pore throat plugging mechanisms to describe the asphaltene deposition. Several assumptions including one-dimensional flow, no gravity force and single liquid phase were considered for mathematical modeling.

The momentum balance (Eq. 4) and mass balance equations in liquid phase for miscible fluid and asphaltene (Eqs. 5 and 6) considered as follows [33]:

$$
\begin{gathered}
\frac{\partial}{\partial t}\left(\emptyset \rho_{l} w_{f l}\right)+\frac{\partial}{\partial x}\left(\rho_{l} u_{l} w_{f l}\right)=0 \\
\frac{\partial}{\partial t}\left(\emptyset \rho_{l} w_{S A l}+\emptyset \rho_{l} w_{A l}\right)+\frac{\partial}{\partial x}\left(\rho_{l} u_{l} w_{S A l}+\rho_{l} u_{l} w_{A l}\right) \\
=-\rho_{A} \frac{\partial E_{A n}}{\partial t}
\end{gathered}
$$

$$
\begin{gathered}
E_{A n}=E_{A}-N_{A} \\
N_{A}=\frac{10^{-9} \cdot C_{n} \cdot q_{L P}}{\rho_{A}} \\
q_{L P}=\frac{q_{\max } \cdot A_{n} \cdot k_{L} \cdot C_{E P}}{1+k_{L} \cdot C_{E P}} \\
C_{E P}=10^{6} \cdot \rho_{l} \cdot C_{A}
\end{gathered}
$$

where $E_{A}$ is the volume fraction of the deposited asphaltene in the bulk volume of the sand pack, $E_{A n}$ is the volume fraction of the deposited asphaltene in the bulk volume after adsorption of asphaltene with nanoparticles, $N_{A}$ is the volume fraction of the adsorbed asphaltene with nanoparticles in the bulk volume of the porous media, $C_{n}$ is the concentration of nanoparticles in crude oil, $A_{n}$ is the surface area of nanoparticles, $q_{L p}$ is the adsorption amounts of asphaltene with zeolite beta nanoparticles in porous media that was calculated by Langmuir model, $C_{E P}$ is the mass fraction of the asphaltene content in the bulk volume of the sand pack, $C_{A}$ is the mass fraction of the asphaltene content in the liquid phase, $q_{\max }$ and $k_{L}$ are the Langmuir adsorption parameters that were obtained from batch adsorption experiments, $w_{f t}$ is the mass fraction of the miscible fluid in the liquid phase, $\rho_{l}$ and $\rho_{A}$ are the liquid and asphaltene densities, respectively, $\emptyset$ is the porosity, $u_{l}$ is the liquid velocity, $w_{A l}$ and $w_{S A l}$ are the mass fractions of the dissolved and suspended asphaltene in the liquid phase, respectively.

The amount of dissolved asphaltene in the liquid phase was calculated by multiphase flash calculations and the Peng-Robinson equation of state was used for this purpose [34]. Subsequently, the asphaltene deposition model was used as follows [33]:

$$
\frac{\partial E_{A}}{\partial t}=\alpha \emptyset w_{S A l} \frac{\rho_{l}}{\rho_{A}}-\beta E_{A}\left(v-v_{c r}\right)+\gamma u_{l} w_{S A l} \frac{\rho_{l}}{\rho_{A}}
$$

where $\alpha, \beta$ and $\gamma$ are the surface deposition rate, entrainment rate and pore throat plugging rate coefficients, respectively, $v\left(=u_{l} / \varphi\right)$ and $v_{c r}$ are the interstitial and critical interstitial velocity of liquid phase, respectively. The value of $\beta$ is described as follows:

$$
\begin{aligned}
& \beta=\beta_{i}: v>v_{c r} \\
& \beta=0: v<v_{c r}
\end{aligned}
$$

The value of $\gamma$ is set as follows:

$$
\gamma=\gamma_{i}\left(1+\sigma E_{A}\right) \quad: D_{p t} \leq D_{p t c r}
$$




$$
\gamma=0: \quad D_{p t}>D_{p t c r}
$$

where $\sigma$ is the snowball-effect deposition constant, $D_{p t}$ and $D_{\text {ptcr }}$ are the pore throat diameter and critical pore throat diameter, respectively.

The porosity and permeability changes during asphaltene deposition process were calculated as follows:

$$
\begin{aligned}
\emptyset & =\emptyset_{0}-E_{A n} \\
k & =k_{0}\left(\frac{\emptyset}{\emptyset_{0}}\right)
\end{aligned}
$$

where $k$ is the permeability, $\emptyset$ is the porosity, $n$ is an adjustable constant and subscript 0 is refer to initial value.

Above equations were coupled and discretized by implicit finite difference method and solved by using an iteration calculation program. Numerical solution was carried out in a cartesian system with 100 grid blocks and 85 time steps with a $\Delta \mathrm{t}$ of $100 \mathrm{~s}$. The genetic algorithm technique was used for optimization and determination of the model parameters $(\alpha$, $\left.\beta, \gamma_{i}, v_{c r}, D_{p t c r}, \sigma, n\right)$. The square root of the summation of the differences between experimental and calculated permeability ratio and porosity ratio data was defined as an objective function:

$$
\begin{aligned}
F_{o b j} & =w_{1} \sum_{i=1}^{N e}\left(\left(\frac{k}{k_{0}}\right)_{\text {exp. } i}-\left(\frac{k}{k_{0}}\right)_{\text {Model }, i}\right)^{2}+(1 \\
& \left.-w_{1}\right) \sum_{i=1}^{N e}\left(\left(\frac{\varphi}{\varphi_{0}}\right)_{\text {exp. } i}-\left(\frac{\varphi}{\varphi_{0}}\right)_{\text {Model }, i}\right)^{2}
\end{aligned}
$$

where $\mathrm{Ne}$ is the number of experimental data, and $w_{1}$ is the weight of the permeability sentence in the objective function.

The initial and boundary conditions for numerical solution were considered as follows:

$$
\begin{gathered}
E_{A}=0 ; \quad \emptyset=\emptyset_{0} ; \quad k=k_{0}: \quad 0<x<L, \quad t=0 \\
v=\frac{Q}{A}: \quad x=0, \quad t>0 \\
p=p_{\text {ambient }}: \quad x=L, \quad t>0
\end{gathered}
$$

where $Q$ is fluid flow rate $\left(\mathrm{cm}^{3} / \mathrm{s}\right)$, and $A$ is cross-sectional area of the sand pack $\left(\mathrm{cm}^{2}\right)$.

\section{RESULTS AND DISCUSSION}

\subsection{Equilibrium Adsorption Experiment Results}

For estimating the proper amount of nanoparticles for asphaltene adsorption from asphaltene-toluene solution, different concentrations of zeolite beta nanoparticles in

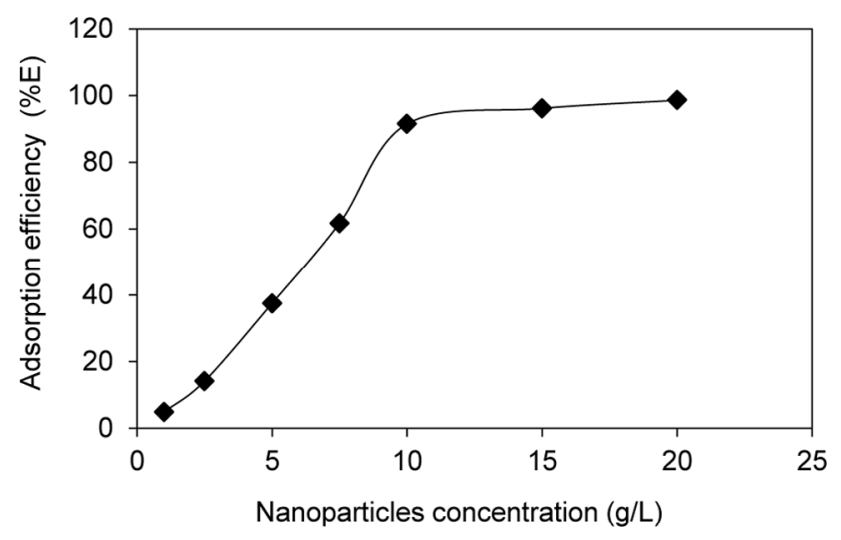

Figure 2

Adsorption efficiency results versus concentration of zeolite beta nanoparticles in solution.

solution were prepared and used. Figure 2 shows the adsorption efficiency versus the concentrations of zeolite beta nanoparticles. All adsorption experiments were replicated three times with the maximum uncertainty of $\pm 5 \%$.

It can be observed that with increasing the nanoparticle concentrations until $10 \mathrm{~g} / \mathrm{L}$, the adsorption efficiency was increased. This may be due to the fact that the higher amounts of zeolite beta nanoparticles provided more active surface for adsorption [35]. However, at the concentrations higher than $10 \mathrm{~g} / \mathrm{L}$ nanoparticles in solution, the adsorption efficiency did not change too much. There are several works in the literature $[11,14,19,26,36]$ concerning the asphaltene adsorption by using nanoparticles with the concentration of $10(\mathrm{~g} / \mathrm{L})$. Therefore, the proper amount of zeolite beta nanoparticles was selected $10 \mathrm{~g} / \mathrm{L}$.

Figure 3 shows the adsorption amounts of asphaltene with the use of $10 \mathrm{~g} / \mathrm{L}$ zeolite beta nanoparticles versus the equilibrium concentrations of asphaltene in the solutions. This figure demonstrates that the adsorption of asphaltene increased widely at lower asphaltene concentrations and reached to constant value by increasing the asphaltene concentrations. This characteristic confirmed the monolayer adsorption of asphaltene onto nanoparticles [25]. Therefore the Langmuir adsorption equation was used to model the equilibrium asphaltene adsorption data. As can be seen in Figure 3, the asphaltene adsorption data were described very well by Langmuir model $\left(\mathrm{R}^{2}>0.99\right)$.

The Langmuir parameters $\left(k_{L}\right.$, qmax $)$ were determined by linearizing. The $k_{L}$ value was found to be $0.0089 \mathrm{~L} / \mathrm{mg}$ and the maximum equilibrium adsorbed asphaltene onto zeolite beta nanoparticles $\left(q_{\max }\right)$ was found to be $1.98 \mathrm{mg} / \mathrm{m}^{2}$. In comparison of the ability of zeolite beta nanoparticles in this study to another nanoparticles, the maximum amounts of adsorbed asphaltene for the Langmuir adsorption on some nanoparticles $\left(\mathrm{mg} / \mathrm{m}^{2}\right)$ are reported in Table 4 . It can be 


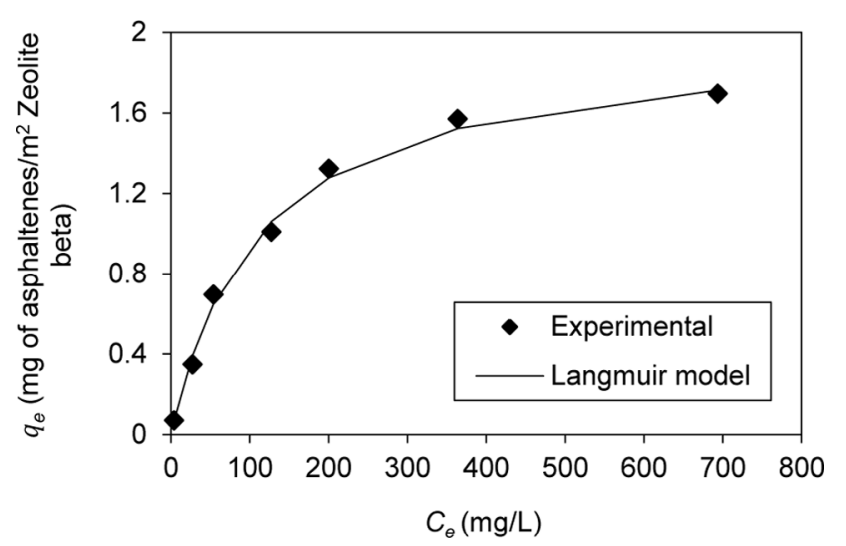

Figure 3

Adsorption amounts of asphaltene onto zeolite beta nanoparticles (the symbol is experimental data, and the solid line is the best fit of the Langmuir model).

TABLE 4

Maximum amounts of adsorbed asphaltene by several nanoparticles.

\begin{tabular}{l|l|l}
\hline Nanoparticles & $\begin{array}{l}q_{\max } \\
\left(\mathrm{mg} / \mathrm{m}^{2}\right)\end{array}$ & Ref. \\
\hline $\begin{array}{l}\text { Zeolite beta (Zeolyst international } \\
\text { company) }\end{array}$ & 1.98 & This study \\
\hline $\begin{array}{l}\mathrm{TiO}_{2} \text { (Nanostructured \& Amorphous } \\
\text { Materials) }\end{array}$ & 0.54 & {$[11]$} \\
\hline $\begin{array}{l}\mathrm{Fe}_{3} \mathrm{O}_{4} \text { (Nanostructured \& Amorphous } \\
\text { Materials) }\end{array}$ & 1.7 & {$[11]$} \\
\hline $\begin{array}{c}\mathrm{Co}_{3} \mathrm{O}_{4} \text { (Nanostructured \& Amorphous } \\
\mathrm{Materials}\end{array}$ & 1.76 & {$[11]$} \\
\hline$\gamma-\mathrm{Fe}_{2} \mathrm{O}_{3}$ (synthesized) & 1.36 & {$[26]$} \\
\hline$\alpha-\mathrm{Fe}_{2} \mathrm{O}_{3}$ (synthesized) & 0.66 & {$[26]$} \\
\hline $\mathrm{Zro}_{2}$ (synthesized) & 1.23 & {$[25]$} \\
\hline $\mathrm{CaCO}_{3}$ (synthesized) & 2.17 & {$[25]$} \\
\hline $\mathrm{Silica}_{\text {gel (Sigma-Aldrich) }}$ & 0.312 & {$[20]$} \\
\hline $\mathrm{Al}_{2} \mathrm{O}_{3}$ (Petroraza) & 1.42 & {$[20]$} \\
\hline
\end{tabular}

observed that the zeolite beta nanoparticles had a relatively good adsorption capacity for asphaltene adsorption from solutions. This result may be due to high surface area and acidic surface of zeolite beta nanoparticles [25].

\subsection{Dynamic Experiment Results}

\subsubsection{Measurement of Pressure Differences}

The aim of two dynamic experiments (DE-2 and DE-1) was to investigate the asphaltene deposition in a sand pack during the co-injection of $\mathrm{n}$-heptane and crude oil solution with and without the use of zeolite beta nanoparticles,

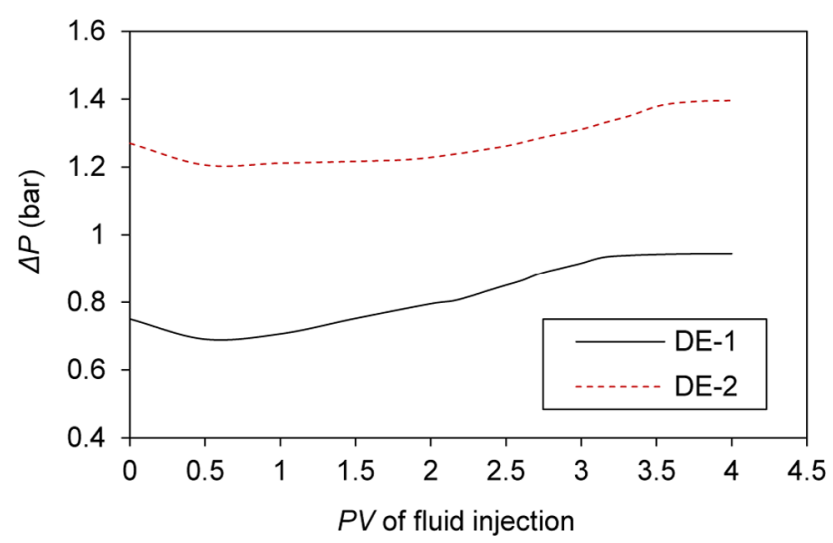

Figure 4

$\Delta \mathrm{P}$ results between two ends of the sand pack.

respectively. Figure 4 shows the recorded $\Delta P$ between two ends of the sand pack during fluid injection. It could be observed in both experiments, the $\Delta P$ decreased until near $1 P V$ of fluid injection. Co-injection of $\mathrm{n}$-heptane and oil into the sand pack, which was previously saturated with the oil, caused a decrease of the fluid viscosity. Therefore, the $\Delta P$ values decreased until the miscibility occurred and a single phase was formed. An increase in $\Delta P$ values after $1 P V$ of fluid injection in the DE-1 indicated the formation damage. The n-heptane injection causes changing the equilibrium conditions and deposition of asphaltene in the sand pack. The increasing of $\Delta P$ values in DE- 1 continued until $3 P V$ of fluid injection. However, in DE-2, the $\Delta P$ was relatively constant until $2 P V$ of fluid injection. After that slow increasing was seen in the $\Delta P$ values until $3.5 P V$ of fluid injection. Therefore, it can be resulted that the zeolite beta nanoparticles can delay the asphaltene deposition about $1 P V$ of fluid injection. It can be seen, $\Delta P$ values in DE- 1 and DE2 experiments were stabled at about 3 and $3.5 P V$ of fluid injection, respectively. Actually, the zeolite beta nanoparticles reduced the slope of increasing trend of $\Delta P$ due to asphaltene deposition in the sand pack.

It must be noted that the higher values of the $\Delta P$ in DE-2 with respect to DE-1 (Fig. 4) can be justified due to higher viscosity value of the crude oil/nanofluid solution and it is not related to more formation damage in the presence of zeolite.

\subsubsection{Calculation of Permeability Ratio}

During the dynamic experiments, permeability was calculated from the measured $\Delta P$ and mixture viscosity by Darcy's law. It can be seen in Figure 5 that the permeability ratio values decreased by increasing the $P V$ of fluid injection. This confirms the asphaltene deposition occurring in nheptane injection experiment. Before miscibility condition 


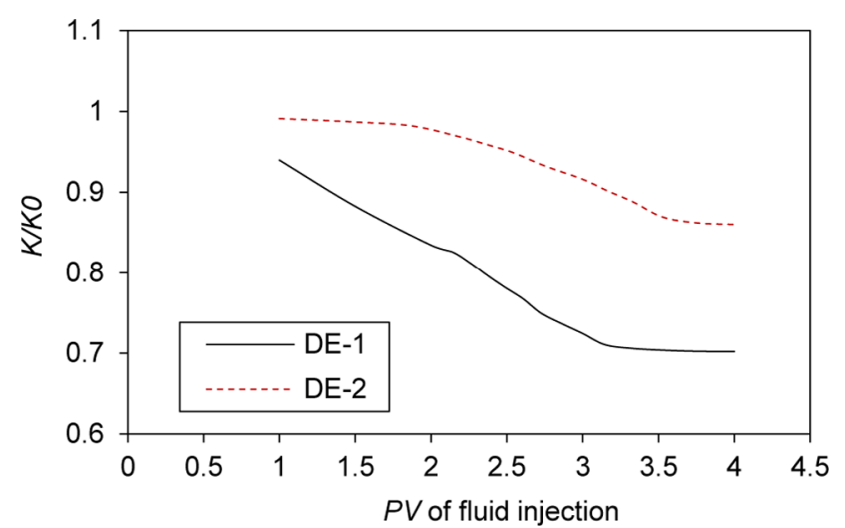

Figure 5

Permeability ratio results during fluid injection experiment.

( $<1 P V$ of fluid injection in this research), the permeability data could not be estimated because the viscosity of fluid was unknown.

Comparing the permeability curve in this research and literature [37] showed that in DE-1, the pore plugging was occurred immediately after miscibility $(>1 P V$ of fluid injection). But in DE-2, most of the asphaltene adsorbed onto nanoparticles surfaces and the remaining asphaltene deposited onto the surface of the silica sands. By increasing the $P V$ of fluid injection in the DE-2 $(>2 P V$ of fluid injection), the asphaltene deposition was increased and the plugging of pores was gradually occurred in the sand pack according to limited capacity of nanoparticles for asphaltene adsorption. After $3 P V$ of fluid injection in DE-1 and after $3.5 P V$ of fluid injection in DE-2, the permeability ratios were not reduced. It is maybe due to that the deposited asphaltene decreased the cross-section of the flow in the sand pack. So the fluid velocity became higher than critical velocity. Therefore, the entrainment of deposited asphaltene in the sand pack occurred and consequently the permeability ratio was not decreased. As observed in Figure 5, the zeolite beta nanoparticles can increase the permeability ratio about $22 \%$ during $\mathrm{n}$-heptane injection into the sand pack.

\subsubsection{Determination of Outlet Fluid's Asphaltene Content and Porosity Ratio}

The asphaltenes were extracted from the outlet fluid samples after specified $P V$ of fluid injection based on the IP-143 standard analysis [21]. The asphaltene content ( $\mathrm{wt} \%)$ of the outlet fluid was calculated by dividing the weight of the extracted asphaltenes to the weight of the crude oil in the outlet sample. The asphaltene content of the outlet fluid after miscibility condition is shown in Figure 6.

It can be observed that the amounts of outlet asphaltene decreased during initial $P V$ of fluid injection both in DE-1 and DE-2. But decreasing rate of outlet asphaltene in DE-1 was higher than in DE-2. The asphaltene content of outlet

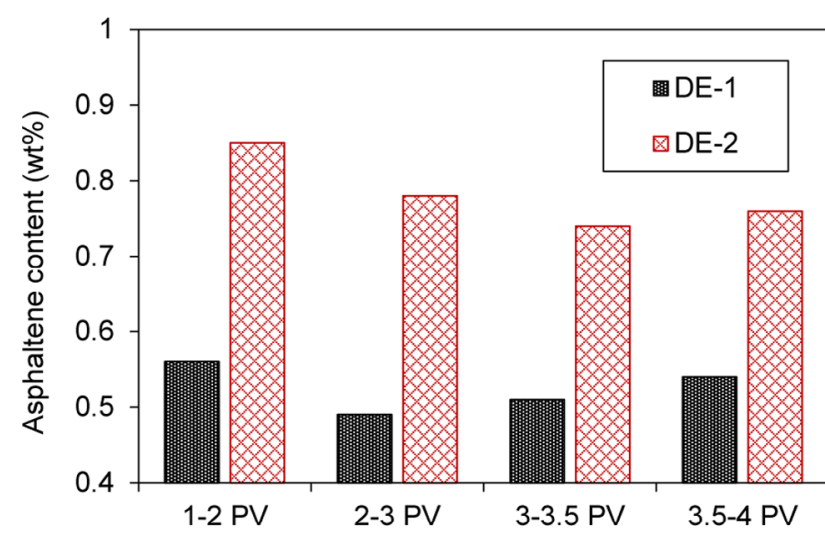

Figure 6

Outlet fluid's asphaltene content (wt \%).

fluid without nanoparticles (DE-1) decreased from $1 \mathrm{wt} \%$ for initial concentration of asphaltene to about $0.54 \mathrm{wt} \%$. But in the case of using nanoparticles (DE-2), the outlet asphaltene content decreased from $1 \mathrm{wt} \%$ to about $0.76 \mathrm{wt} \%$ resulting in an increase of the outlet asphaltene. In addition, it can be seen after $3 P V$ of fluid injection in DE-1 and after 3.5 $P V$ of fluid injection in DE-2, the outlet asphaltene content was slightly increased because of occurring entrainment of deposited asphaltene. As observed in Figure 6, the zeolite beta nanoparticles increased the outlet fluid's asphaltene content about $40 \%$ comparing to DE- 1 results. Because a part of asphaltene content adsorbed onto nanoparticles surfaces during fluid injection in the DE-2 experiment and it exited from the sand pack by flow. Therefore, the amount of deposited asphaltene ( $\approx$ difference between asphaltene content in the outlet and inlet fluids) in the sand pack was decreased with the use of zeolite beta nanoparticles in the fluid injection experiment (Fig. 7).

In addition, the porosity ratio at specified pore volume of the fluid injection was calculated by dividing the differences between initial pore volume and deposited asphaltene volume to the bulk volume. It must be noticed that the volume of deposited asphaltene was calculated by dividing the mass differences of inlet and outlet asphaltene to the asphaltene density. The asphaltene density was equal to $1.0106 \mathrm{~g} / \mathrm{cm}^{3}$. The porosity ratio results are shown in Figure 7. It can be observed the porosity ratio reduced to about 0.985 and 0.991 in DE-1 and DE-2, respectively. The less porosity reduction comparing to permeability reduction during fluid injection is indicated to asphaltene deposition in the local positions instead along the sand pack [38].

\subsection{Dynamic Modeling Results}

A model based on the adding adsorption term to the Wang and Civan deposition model [33] was presented for calculating of permeability and porosity ratios in the case of using 


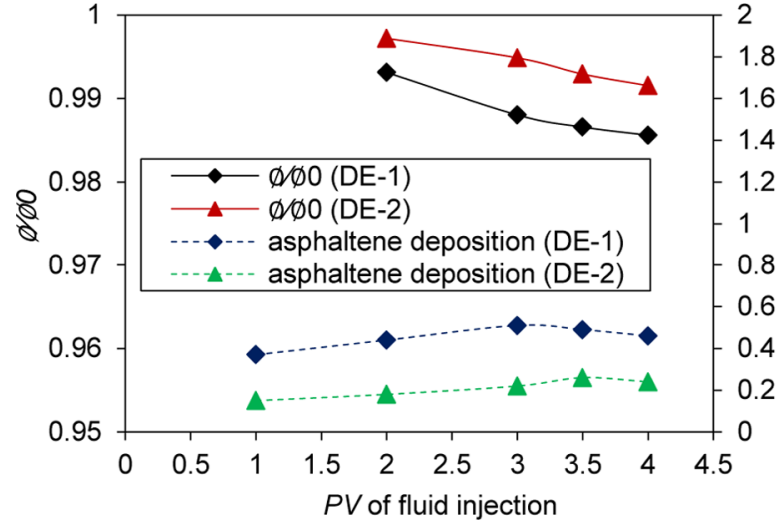

Figure 7

Porosity ratio and asphaltene deposition results during fluid injection experiments.

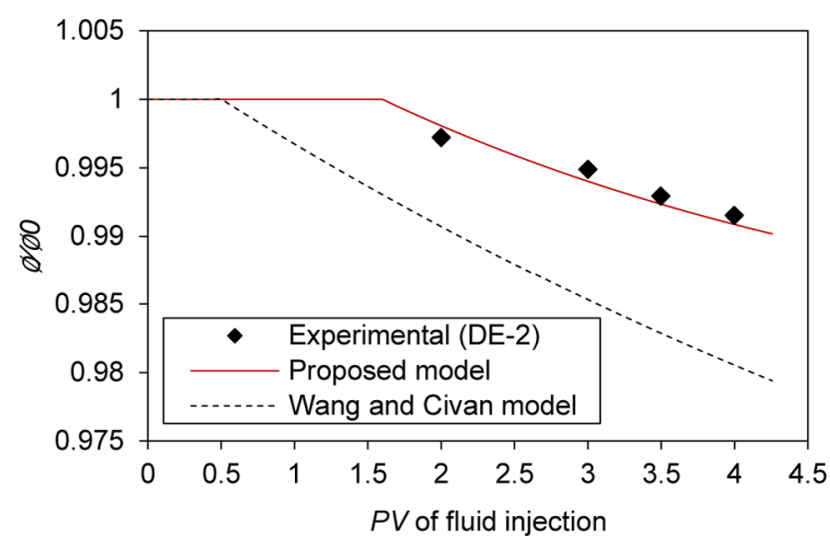

Figure 8

Comparison of the porosity ratios experimental data and predictions of the proposed model and Wang and Civan model.

nanoparticles in porous media (DE-2). The calculated porosity and permeability ratios by using proposed model and Wang and Civan model are shown in Figures 8 and 9, respectively.

The modeling results in Figures 8 and 9 confirmed that the nanoparticles can improve the porosity and permeability ratios during fluid injection test. It can be observed that the results of permeability and porosity ratios by the proposed model were in good agreement with experimental data. The average absolute deviation (AAD\%) of the calculated permeability and porosity ratios from the experimental results with using both models were determined and the adjusted parameters of the models that obtained from genetic algorithm technique are reported in Table 5. It was found that the proposed model is capable of predicting the permeability ratios in DE-2 with $\mathrm{AAD} \%$ of 1.07 . Whereas permeability ratio prediction based on the Wang and Civan model is less accurate with $\mathrm{AAD} \%$ of $2.25 \%$. In addition, the proposed model can predict the porosity ratios in DE-2 with high accuracy $(\mathrm{AAD} \%=0.07)$. But the Wang and Civan model predicted porosity ratios with

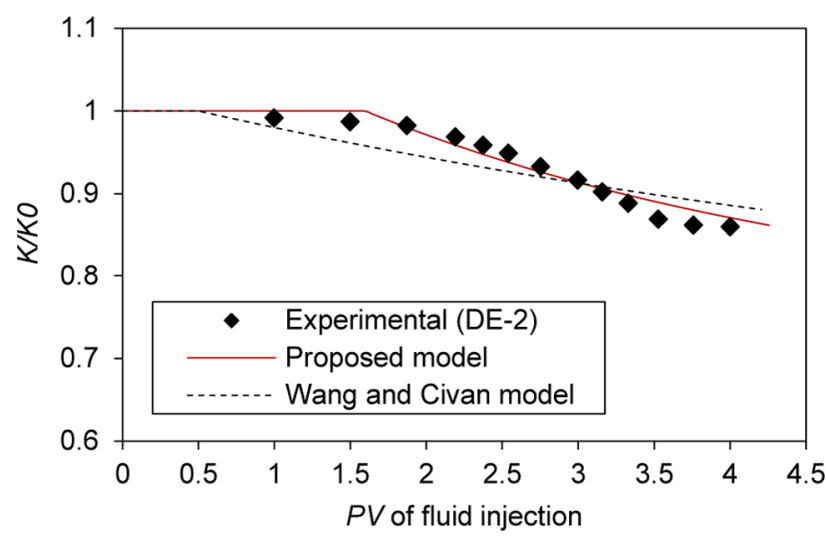

Figure 9

Comparison of the permeability ratios experimental data and predictions of the proposed model and Wang and Civan model.

TABLE 5

Adjusted parameters of asphaltene deposition models in DE-2 experiment.

\begin{tabular}{c|l|l}
\hline Parameters & Proposed model & Wang and Civan model [33] \\
\hline$\alpha(1 / \mathrm{s})$ & 0.0004 & 0.0005 \\
\hline$\beta(1 / \mathrm{cm})$ & 0.0171 & 0.0207 \\
\hline$\gamma_{i}(1 / \mathrm{cm})$ & 0.0153 & 0.0019 \\
\hline$v_{c r}(\mathrm{~cm} / \mathrm{s})$ & 0.0001 & 0.0049 \\
\hline$D_{p t c r}(\mathrm{~cm})$ & 0.0010 & 0.0045 \\
\hline$\sigma$ & & \\
\hline$n$ & 0.0366 & 0.0972 \\
\hline
\end{tabular}

$\mathrm{AAD} \%$ of 0.94 . So, it can be concluded that the proposed model in study, can use as a suitable model for modeling the asphaltene deposition during fluid injection with the use of nanoparticles in the porous media.

\section{CONCLUSION}

At first, a series of experiments including equilibrium asphaltene adsorption onto zeolite beta nanoparticles was conducted by UV-Vis spectrophotometer to determine the adsorption capacity of nanoparticles. The adsorption experimental results showed that the zeolite beta can efficiently adsorb asphaltene from solution. It was found that, an adsorption isotherm good matched by the Langmuir model, suggesting a monolayer asphaltene adsorption onto zeolite. Special properties of zeolite beta nanoparticles such as high surface area to volume ratio and high functionalizable 
surface cause good adsorption capacity for the zeolite beta. The results of adsorption efficiency showed that the proper concentration of nanoparticles for asphaltene adsorption was equal to $10 \mathrm{~g} / \mathrm{L}$ zeolite beta in the oil. However, in order to determine the economically optimum amount of nanoparticles in the industry, the economic aspect should be evaluated. In addition, two dynamic experiments including co-injection of crude oil and n-heptane into a silica sand pack were conducted with and without the use of zeolite beta nanoparticles. The purpose of dynamic experiments was to investigate the effect of the zeolite beta nanoparticles on reduction of formation damage during oil injection in porous media. The dynamic experiments showed that zeolite beta could delay the increasing of the $\Delta P$ and reduce the asphaltene deposition. It must be noted that the use of nanoparticles increased the fluid's viscosity and as a result, it increased the total values of the $\Delta P$ compared to the experiment without the use of zeolite beta. Moreover, the results showed that the zeolite beta nanoparticles increased the permeability and porosity ratios and reduced asphaltene deposition during co-injection of crude oil and n-heptane into the silica sand pack. The interactions between the asphaltene particles with their basic nature and acidic surfaces of zeolite beta nanoparticles caused well adsorption of asphaltene and therefore improvement of the formation damage. It can be seen from the modeling results that the proposed model based on the monolayer adsorption of asphaltene onto nanoparticles and three mechanisms of asphaltene deposition (surface deposition, entrainment and pore throat plugging) is more accurate in the prediction of permeability and porosity ratios (AAD\% of 1.07 and 0.07$)$ than the Wang and Civan model (AAD\% of 2.25 and 0.94). This study confirms that the zeolite beta nanoparticles could be used for reducing asphaltene deposition in porous media and finally enhancing oil recovery.

\section{NOMENCLATURE}

AAD average absolute deviation

$A \quad$ cross-sectional area of the sand pack

$A_{n} \quad$ surface area of nanoparticles

$C_{A} \quad$ mass fraction of the asphaltene content in the liquid phase

$C_{0} \quad$ initial concentration of asphaltene in solutions

$C_{e} \quad$ equilibrium concentration of asphaltene in solutions

$C_{n} \quad$ concentration of nanoparticles in crude oil

$C_{E P}$ mass fraction of the asphaltene content in the bulk volume of the sand pack

DE-1 dynamic experiment 1

DE-2 dynamic experiment 2

$D_{p t} \quad$ pore throat diameter

$D_{\text {ptcr }} \quad$ critical pore throat diameter

E adsorption efficiency
$E_{A} \quad$ volume fraction of the deposited asphaltene in the bulk volume of the sand pack

$E_{A n} \quad$ volume fraction of the deposited asphaltene in the bulk volume after adsorption of asphaltene on nanoparticles

$F_{o b j} \quad$ objective function

$k \quad$ permeability

$k_{0} \quad$ initial permeability

$k_{L} \quad$ Langmuir equilibrium adsorption constant $(\mathrm{L} / \mathrm{mg})$

$L \quad$ length of the sand pack

MW molecular weight

$m \quad$ dry mass of nano-particles

$n \quad$ adjustable parameter

$\mathrm{Ne}$ number of experimental data

$N_{A} \quad$ volume fraction of the adsorbed asphaltene with nanoparticles in the bulk volume of the porous media

$P \quad$ pressure

$\Delta P \quad$ pressure differences

$P V$ pore volume

$Q \quad$ fluid flow rate

$q_{e} \quad$ equilibrium adsorbed amount of asphaltene

$q_{\max }$ maximum amount of adsorbed asphaltene for the Langmuir adsorption on adsorbent surfaces

$q_{L P} \quad$ Langmuir adsorption amounts of asphaltene with nanoparticles in porous media

$R^{2} \quad$ correlation coefficient

$S G \quad$ specific gravity

swi irreducible water saturation

$t$ time

$u_{l} \quad$ liquid velocity

$V \quad$ volume of solution

$w_{1} \quad$ weight of the permeability sentence in objective function

$w_{A l}$ mass fractions of the dissolved asphaltene in the liquid phase

$w_{S A l}$ mass fractions of the suspended asphaltene in the liquid phase

$w_{f l} \quad$ mass fraction of the miscible fluid in the liquid phase

$w t \% \quad$ weight fraction percent

\section{GREEK SYMBOLS}

$\alpha \quad$ surface deposition rate coefficient

$\beta$ entrainment rate coefficient

$\gamma$ pore throat plugging rate coefficient

$\delta \quad$ snowball-effect deposition constant

$\mu$ fluid viscosity

$\rho$ density

$\rho_{l} \quad$ liquid density

$\rho_{A}$ asphaltene density

$\varphi$ porosity

$\varphi_{0} \quad$ initial porosity

$v$ interstitial velocity of liquid phase

$v_{c r}$ critical interstitial velocity of liquid phase 


\section{REFERENCES}

1 Jafari Behbahani T., Ghotbi C., Taghikhani V., Shahrabadi A. (2015) Experimental study and mathematical modeling of asphaltene deposition mechanism in core samples, Oil Gas Sci. Technol. - Rev. IFP 70, 6, 1051-1074.

2 Buckley J.S. (1998) Wetting alteration of solid surfaces by crude oils and their asphaltenes, Oil Gas Sci. Technol. - Rev. IFP 53, 3, 303-312.

3 Karambeigi M.A., Kharrat R. (2014) An investigation of inhibitors performance on asphaltene precipitation due to associated gas injection, Petrol. Sci. Technol. 32, 10, 1213-1218.

4 Kashefi S., Shahrabadi A., Jahangiri S., Lotfollahi M.N., Bagherzadeh, H. (2016) Investigation of the performance of several chemical additives on inhibition of asphaltene precipitation, Energy Sour. Part A Recovery Util. Environ. Eff. 38, 24, 3647-3652.

5 Kashefi S., Shahrabadi A., Lotfollahi M.N., Varamesh, A. (2016) A new polymeric additive as asphaltene deposition inhibitor in $\mathrm{CO}_{2}$ core flooding, Korean J. Chem. Eng. 33, 11, 3273-3280.

6 Marczewski A.W., Szymula M. (2002) Adsorption of asphaltenes from toluene on mineral surface, Colloids Surf. A: Physicochem. Eng. Asp. 208, 1, 259-266.

7 Pernyeszi T., Patzko A., Berkesi O., Dékány I. (1998) Asphaltene adsorption on clays and crude oil reservoir rocks, Colloids Surf. A: Physicochem. Eng. Asp. 137, 1, 373-384.

8 Dudášová D., Simon S., Hemmingsen P.V., Sjöblom, J. (2008) Study of asphaltenes adsorption onto different minerals and clays: Part 1. Experimental adsorption with UV depletion detection, Colloids Surf. A: Physicochem. Eng. Aspects 317, 1, $1-9$.

9 Ekholm P., Blomberg E., Claesson P., Auflem I.H., Sjöblom J., Kornfeldt A. (2002) A quartz crystal microbalance study of the adsorption of asphaltenes and resins onto a hydrophilic surface, J. Colloid Interface Sci. 247, 2, 342-350.

10 Abdallah W.A., Taylor S.D. (2007) Surface characterization of adsorbed asphaltene on a stainless steel surface, Nucl. Instrum. Meth. B 258, 1, 213-217.

11 Nassar N.N., Hassan A., Pereira-Almao P. (2011) Metal oxide nanoparticles for asphaltene adsorption and oxidation, Energy Fuels 25, 3, 1017-1023.

12 Nassar N.N., Hassan A., Pereira-Almao P. (2011) Effect of surface acidity and basicity of aluminas on asphaltene adsorption and oxidation, J. Colloid Interface Sci. 360, 1, 233-238

13 Nassar N.N., Hassan A., Carbognani L., Lopez-Linares F., Pereira-Almao P. (2012) Iron oxide nanoparticles for rapid adsorption and enhanced catalytic oxidation of thermally cracked asphaltenes, Fuel 95, 257-262.

14 Nassar N.N. (2010) Asphaltene adsorption onto alumina nanoparticles: kinetics and thermodynamic studies, Energy Fuels 24, 8, 4116-4122.

15 Hashemi R., Nassar N.N., Pereira-Almao P. (2012) Transport behavior of multimetallic ultradispersed nanoparticles in an oil-sands-packed bed column at a high temperature and pressure, Energy Fuels 26, 3, 1645-1655.

16 Mirzayi B., Shayan N.N. (2014) Adsorption kinetics and catalytic oxidation of asphaltene on synthesized maghemite nanoparticles, J. Petrol. Sci. Eng. 121, 134-141.
17 Kazemzadeh Y., Eshraghi S.E., Kazemi K., Sourani S., Mehrabi M., Ahmadi Y. (2015) Behavior of asphaltene adsorption onto the metal oxide nanoparticles surface and its effect on the heavy oil recovery, Ind. Eng. Chem. Res. 54, 1, 233-239.

18 Hashemi S.I., Fazelabdolabadi B., Moradi S., Rashidi A.M., Shahrabadi A., Bagherzadeh H. (2016) On the application of $\mathrm{NiO}$ nanoparticles to mitigate in situ asphaltene deposition in carbonate porous matrix, Appl. Nanosci. 6, 1, 71-81.

19 Franco C., Patiño E., Benjumea P., Ruiz M.A., Cortés F.B. (2013) Kinetic and thermodynamic equilibrium of asphaltenes sorption onto nanoparticles of nickel oxide supported on nanoparticulated alumina, Fuel 105, 408-414.

20 Franco C.A., Nassar N.N., Ruiz M.A., Pereira-Almao P., Cortes F.B. (2013) Nanoparticles for inhibition of asphaltenes damage: adsorption study and displacement test on porous media, Energy Fuels 27, 6, 2899-2907.

21 ASTM D6560. (2005) Standard test method for determination of asphaltenes (heptane insolubles) in crude petroleum and petroleum products. Annual Book of ASTM Standards, American Society for Testing and Materials, Philadelphia, PA, 5(3).

22 Fan T., Buckley J.S. (2006) Acid number measurements revisited, SPE/DOE Symposium on Improved Oil Recovery, Tulsa, Oklahoma, 22-26 April, SPE Paper 99884-MS.

23 Saadatjoo N., Golshekan M., Shariati S., Kefayati H., Azizi P. (2013) Organic/inorganic MCM-41 magnetite nanocomposite as a solid acid catalyst for synthesis of benzo $[\alpha]$ xanthenone derivatives, J. Mol. Catal. A: Chem. 377, 173-179.

24 Yudin I.K., Nikolaenko G.L, Gorodetskii E.E., Kosov V.I., Melikyan V.R., Markhashov E.L., Frot D., Briolant Y. (1998) Mechanisms of asphaltene aggregation in toluene-heptane mixtures, J. Petrol. Sci. Eng. 20, 3, 297-301.

25 Hosseinpour N., Khodadadi A.A., Bahramian A., Mortazavi Y. (2013) Asphaltene adsorption onto acidic/basic metal oxide nanoparticles toward in situ upgrading of reservoir oils by nanotechnology, Langmuir29, 46, 14135-14146.

26 Shayan N.N., Mirzayi B. (2015) Adsorption and removal of asphaltene using synthesized maghemite and hematite nanoparticles, Energy Fuels 29, 3, 1397-1406.

27 Langmuir I. (1916) The constitution and fundamental properties of solids and liquids. Part I. Solids, J. Am. Chem. Soc. 38, 11, 2221-2295.

28 Mohammadi M., Akbari M., Fakhroueian Z., Bahramian A., Azin R., Arya S. (2011) Inhibition of asphaltene precipitation by $\mathrm{TiO}_{2}, \mathrm{SiO}_{2}$, and $\mathrm{ZrO}_{2}$ nanofluids, Energy Fuels 25, 7, 3150-3156.

29 Haddad Z., Abid C., Oztop H.F., Mataoui A. (2014) A review on how the researchers prepare their nanofluids, Int. J. Therm. Sci. 76, 168-189.

30 Jafari Behbahani T., Ghotbi C., Taghikhani V., Shahrabadi A. (2012) Investigation on asphaltene deposition mechanisms during $\mathrm{CO}_{2}$ flooding processes in porous media: a novel experimental study and a modified model based on multilayer theory for asphaltene adsorption, Energy Fuels 26, 8, 5080-5091.

31 Papadimitriou N.I., Romanos G.E., Charalambopoulou G. Ch., Kainourgiakis M.E., Katsaros F.K., Stubos A.K. (2007) Experimental investigation of asphaltene deposition mechanism during oil flow in core samples, J. Petrol. Sci. Eng. 57, 3, 281-293. 
32 Bagherzadeh H., Ghazanfari M.H., Kharrat R., Rashtchian D. (2014) Experimental investigation and modeling of permeability impairment mechanisms due to asphaltene precipitation under $\mathrm{CO}_{2}$ injection conditions, Energy Sour. Part A Recovery Util. Environ. Eff. 36, 6, 591-604.

33 Wang S., Civan F. (2001) Productivity decline of vertical and horizontal wells by asphaltene deposition in petroleum reservoirs, SPE International Symposium on Oilfield Chemistry, Houston, Texas, 13-16 Feb., SPE paper 64991-MS.

34 Kashefi S., Lotfollahi M.N., Shahrabadi A. (2017) An investigation of asphaltene deposition mechanisms during natural depletion process by a two phase modeling using genetic algorithm technique, J. Petrol. Sci. Technol. 7, 2, 12-20.

35 Selvin R., Roselin L.S., Khayyat S.A., Umar A. (2013) Hierarchical zeolite beta: An efficient and eco-Friendly nanocatalyst for the friedel-crafts acylation of toluene, $J$. Nanosci. Nanotechnol. 13, 6, 4415-4420.
36 Nassar N.N., Hassan A., Luna G., Pereira-Almao P. (2013) Kinetics of the catalytic thermo-oxidation of asphaltenes at isothermal conditions on different metal oxide nanoparticle surfaces, Catal. Today207, 127-132.

37 Roque C., Chauveteau G., Renard M., Thibault G., Bouteca M., Rochon J. (1995) Mechanisms of formation damage by retention of particles suspended in injection water, SPE European Formation Damage Conference, Hague, Netherlands, 15-16 May, SPE paper 30110-MS.

38 Bagheri M., Kharrat R., Ghotbi C. (2011) Experimental investigation of the asphaltene deposition process during different production schemes, Oil Gas Sci. Technol. - Rev. IFP 66, 3, 507-519.
Manuscript submitted in 8 January 2017 Manuscript accepted in 7 November 2017 Published online in January 2018 